CHRONIC OBSTRUCTIVE PULMONARY DISEASE

\title{
How should COPD patients exercise during respiratory rehabilitation? Comparison of exercise modalities and intensities to treat skeletal muscle dysfunction
}

\author{
M A Puhan, H J Schünemann, M Frey, M Scharplatz, L M Bachmann
}

Thorax 2005;60:367-375. doi: 10.1136/thx.2004.033274

\begin{abstract}
See end of article for authors' affiliations

Correspondence to: Dr M A Puhan, Horten Centre, University Hospital of Zurich, Postfach Nord, $\mathrm{CH}-8091$ Zurich, Switzerland; milo.puhan@ evimed.ch
\end{abstract}

Received 13 August 2004 Accepted 18 January 2005

\begin{abstract}
Background: Physical exercise is an important component of respiratory rehabilitation because it reverses skeletal muscle dysfunction, a clinically important manifestation of COPD associated with reduced healthrelated quality of life (HRQL) and survival. However, there is controversy regarding the components of the optimal exercise protocol. A study was undertaken to systematically evaluate and summarise randomised controlled trials (RCTs) comparing different exercise protocols for COPD patients.

Methods: Six electronic databases, congress proceedings and bibliographies of included studies were searched without imposing language restrictions. Two reviewers independently screened all records and extracted data on study samples, interventions and methodological characteristics of included studies.

Results: The methodological quality of the 15 included RCTs was low to moderate. Strength exercise led to larger improvements of HRQL than endurance exercise (weighted mean difference for Chronic Respiratory Questionnaire $0.27,95 \% \mathrm{Cl} 0.02$ to 0.52 ). Interval exercise seems to be of similar effectiveness as continuous exercise, but there are few data on clinically relevant outcomes. One small RCT which included patients with mild COPD compared the effect of high and low intensity exercise (at $80 \%$ and $40 \%$ of the maximum exercise capacity, respectively) and found larger physiological training effects from high intensity exercise.

Conclusions: Strength exercise should be routinely incorporated in respiratory rehabilitation. There is insufficient evidence to recommend high intensity exercise for COPD patients and investigators should conduct larger high quality trials to evaluate exercise intensities in patients with moderate to severe COPD.
\end{abstract}

\footnotetext{
$\mathrm{C}$
} hronic obstructive pulmonary disease (COPD) is the only cause of death from chronic disease that will increase worldwide until 2020, ${ }^{1}$ and it represents a big burden for patients ${ }^{2}$ and society. ${ }^{3-5}$ Respiratory rehabilitation combining interventions on the respiratory system (smoking cessation), psychological support (coping strategies), and physical exercise improves exercise capacity and healthrelated quality of life (HRQL) ${ }^{6}$ and is cost effective. ${ }^{7}$

Over recent years, investigators and clinicians have increasingly recognised the role of skeletal muscle dysfunction as an indicator of advanced stages of COPD. ${ }^{8-12}$ The physical exercise component has therefore become a cornerstone of respiratory rehabilitation. ${ }^{13-17}$ Several studies have shown that physical exercise reverses COPD induced skeletal muscle dysfunction as well as the morphological and metabolic changes of skeletal muscles. ${ }^{18} 19$ There is, however, substantial variation in exercise protocols used in clinical trials. ${ }^{20-23}$ This variation feeds an ongoing debate on the optimal exercise protocol ${ }^{131924}$ and on how the general effect modifying principles, training intensity, specificity, and reversibility known from healthy subjects ${ }^{25}$ apply to COPD patients. Trial results are conflicting with regard to the intensity at which COPD patients should exercise, how intensity should be determined, and whether continuous or interval exercise is most appropriate. In addition, although most investigators agree that endurance exercise for lower extremities should be the main exercise modality, ${ }^{14}{ }^{24}$ the role of strength and upper body exercise remains unclear.

Previous reviews have focused on the question of whether respiratory rehabilitation (including physical exercise) has any effect in improving exercise capacity and HRQL. Trials addressing this question have compared the intervention against groups without any exercise programme. ${ }^{6}$ These studies did not provide answers on the relative benefits and disadvantages of different exercise protocols. The aim of this systematic review is therefore to analyse all available randomised controlled trials (RCTs) with head to head comparisons of at least two exercise protocols (different exercise modalities and intensities or combinations thereof) to improve exercise capacity and HRQL in patients with COPD.

\section{METHODS}

Identification of studies

We searched MEDLINE (Ovid version, New York, from inception to May 2004), EMBASE (DataStar version, Cary, NC from inception to November 2003), PEDRO (online version, University of Sydney, Australia, November 2003) and the Cochrane Central Register of Controlled Trials (Oxford, UK, 2004, Issue 1) to identify relevant articles. We also searched the Science Citation Index database (Web of Science, Thomson ISI, Philadelphia, PA, USA) and PubMed using its "related articles" function (National Library of Medicine, Bethesda, MD, USA) by entering all included studies. The detailed search strategy is available on request.

Hand searches of the proceedings of the International Conferences of the American Thoracic Society and the congress of the European Respiratory Society, reference checks of bibliographies of all included studies and of reviews on respiratory rehabilitation or physical exercise in patients with COPD that we identified in the literature search, and contacts with authors complemented our searches.

\section{Selection criteria}

We included RCTs comparing different exercise modalities and intensities or combinations thereof that followed 
standardised exercise protocols for patients with COPD. We focused on standardised exercise protocols because only these allow replication in clinical practice. We defined a standardised exercise protocol as the use of an identical exercise activity for all patients (such as treadmill walking, cycle ergometer training, or weight lifting) at measurable exercise intensity (such as Watts, number of repetitions, $\mathrm{kg}$, or percentage of one repetition maximum). Studies were included if more than $90 \%$ of participants had COPD defined according to the following criteria: (1) a clinical diagnosis of COPD; (2) irreversible airways obstruction; and (3) one of the following: (a) best recorded $\mathrm{FEV}_{1} / \mathrm{FVC}$ ratio of individual patients $<0.7$; (b) best recorded $\mathrm{FEV}_{1}$ of individual patients $<70 \%$ of predicted value. We considered the following outcome measures: HRQL as measured by generic (e.g. Short Form-36) or disease specific (e.g. Chronic Respiratory Questionnaire (CRQ)) questionnaires; symptom scales; functional exercise capacity as measured by 2, 4, 6, 12 minute walk test or a shuttle walk test; and maximum exercise capacity as measured by incremental or constant work rate exercise tests on cycle ergometers or treadmills. In addition, we extracted data on exercise tolerance (adherence to exercise protocols, completion of exercise programme, losses to follow up) and on physiological parameters documenting training effects (such as lactate, anaerobic threshold) for studies where no clinical outcomes were available. We did not impose language restrictions.

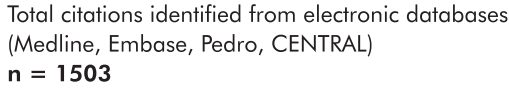

\section{Data extraction and quality assessment}

The bibliographic details of all retrieved articles were stored in a Reference Manager file (Professional Edition Version 10, ISI ResearchSoft, Berkeley, CA, USA) and duplicate records resulting from the various database searches were removed. Two members of the review team independently scrutinised the titles and abstracts of all identified citations (fig l). The full text of any article that was deemed potentially eligible was ordered by one of the reviewers. The two reviewers evaluated the full text of all retrieved papers, made a decision on inclusion or exclusion, and discussed the decisions. Any disagreement was resolved by consensus with close attention to the inclusion/exclusion criteria. Final decisions on papers were recorded in the Reference Manager file and bibliographic details as well as the reasons for exclusion. We recorded the initial degree of discordance between the reviewers and corrected discordant scores based on obvious errors. Discordant scores were resolved based on real differences in interpretation through consensus or third party arbitration.

One reviewer extracted details about study patients, interventions, and outcome measures as well as the results in a predefined data form and the second reviewer checked the data extraction for accuracy. We pilot tested the data forms using five studies with a high likelihood for inclusion. We contacted the authors of the primary studies to obtain missing information. If only the abstract was available without any further information from the authors, the study was excluded from the analysis.

Two reviewers independently evaluated the quality of included trials using a detailed list of quality items assessing components of validity (see data available on the Thorax website at http://www.thoraxjnl.com/supplemental). ${ }^{26}$

\section{Methods of analysis and synthesis}

The results of the data extraction and assessment of study validity were summarised in structured tables to explore the variation in patient characteristics, interventions, outcome measures, study quality and results. Forest plots were used to compare results across the trials. If appropriate, we planned to explore sources of heterogeneity (that is, differences between studies) using multivariable regression models (meta-regression analysis) where a priori defined clinical and methodological items would serve as explanatory variables. A priori defined explanations for heterogeneity across trials were severity of disease, length of intervention ( $<$ or $\geqslant 6$ months), exercise modality (for example, endurance exercise on bicycle or treadmill), exercise intensity (for example, strength exercise with high work load and few repetitions versus low work load and numerous repetitions), exercise tests used to determine exercise load, and comprehensiveness of rehabilitation programme (patient education, psychosocial support, breathing exercises, relaxation therapies).

The trial results were pooled by calculating weighted mean differences. Since random and fixed effect models produced the same results, only the results from fixed effect models are presented. No pooling was undertaken in the presence of significant heterogeneity ( $\mathrm{p}<0.1$ for $\mathrm{Q}$ statistic).

Whenever possible, estimates and confidence limits were related to the minimal important difference (MID) ${ }^{27}$ for each outcome. We assessed whether the estimates and 95\% confidence limits for the difference between study groups exceeded the MID (for the 6 minute walk distance the MID is $\pm 53 \mathrm{~m},{ }^{28} \mathrm{CRQ} \pm 0.5$ on 7 -point scales, ${ }^{29}$ and St George's Respiratory Questionnaire \pm 4 points $^{30}$ ).

All statistical analyses were done with STATA Version 8.2 (Stata Corp, College Station, TX, USA).

Figure 1 Study flow from identification to final inclusion of studies. 


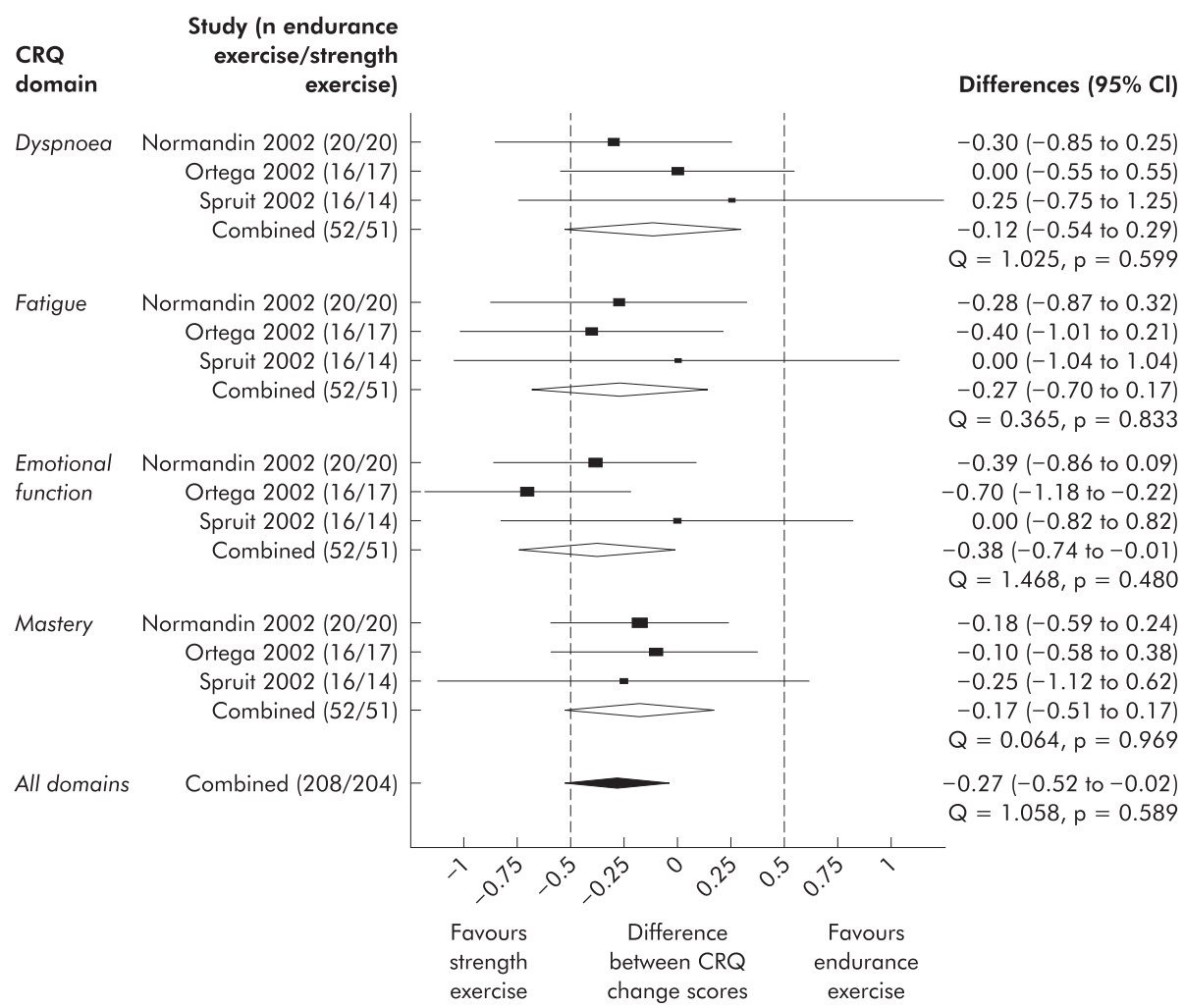

Figure 2 Results from three trials in which the CRQ was used to compare strength exercise with endurance exercise. Boxes with 95\% confidence intervals represent point estimates for the difference between the CRQ change scores (from baseline to follow up) of the study groups. A difference of 0 means that both study groups improved or deteriorated to the same amount. Results are presented per CRQ domain. Dashed lines at \pm 0.5 represent the minimal important difference of the $C R Q$.

\section{RESULTS}

\section{Study selection}

Figure 1 shows the study selection process and agreement on study inclusion. Of the 18 trials fulfilling the inclusion criteria, three were excluded from further analysis because they were published as abstracts and the authors were unable to provide further details. ${ }^{31-33}$

\section{Quality assessment}

The table in the online supplement shows the methodological quality of the included trials. Agreement in the quality

assessment was $90.7 \%$ for all items $(\kappa=0.72)$. In general, most included trials scored poorly on the checklist used. Just one trial ${ }^{34}$ described concealment of random allocation, another trial ${ }^{35}$ used stratification to control for prognostically important variables, and one trial ${ }^{34}$ reported blinding of outcome assessors.

\section{Comparisons of training modalities}

Endurance exercise $v$ strength exercise

Four trials compared endurance and strength exercise (table 1)..$^{34}{ }^{36-38}$ The weighted mean differences showed larger

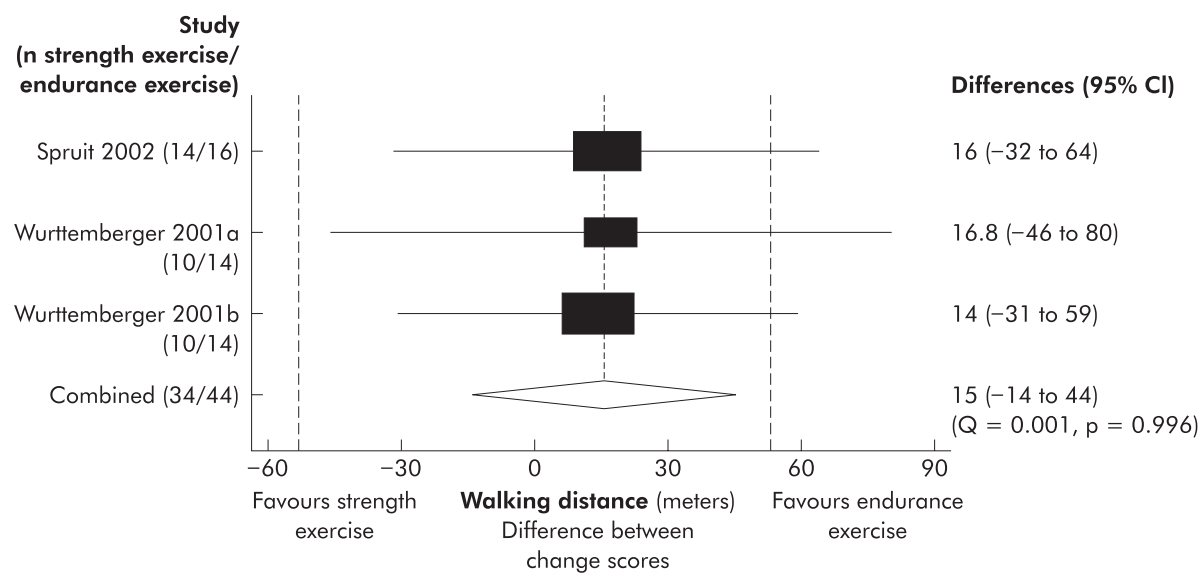

Figure 3 Results from three trials in which walking tests were used to compare strength exercise with endurance exercise. Boxes with $95 \%$ confidence intervals represent point estimates for the difference between the walking distances (from baseline to follow up) of the study groups. A difference of 0 means that both study groups improved or deteriorated to the same amount. Dashed lines at \pm 53 metres represent the minimal important difference of the 6 minute walk test. 
Table 1 Characteristics of randomised controlled trials comparing strength and endurance exercise

\begin{tabular}{|c|c|c|c|c|}
\hline Study & Population & Exercise programmes & Rehabilitation programme & Outcomes \\
\hline Normandin $^{36}$ & $\begin{array}{l}40 \text { COPD patients ( } 53 \% \text { men, } \\
\text { mean } F E V_{1} 49.5 \% \text { predicted, } \\
\text { mean age } 68 \text { years) }\end{array}$ & $\begin{array}{l}\text { Group 1: Continuous ergometer cycling at } 80 \% \text { of } \\
\text { Wmax } \\
\text { Group 2: Low intensity calisthenics for peripheral } \\
\text { muscles (29 stretching and strength exercises, 8-10 } \\
\text { repetitions for each exercise) }\end{array}$ & $\begin{array}{l}\text { Sessions of } 10-30 \text { min, } \\
3 \times / \text { week for } 10 \text { weeks, Edu }\end{array}$ & IET, CWRT, CRQ, TDI, PFSS \\
\hline Ortega ${ }^{37}$ & $\begin{array}{l}47 \text { COPD patients ( } 87 \% \text { men, } \\
\text { mean } F E V_{1} 38.8 \% \text { predicted, } \\
\text { mean age } 64 \text { years) }\end{array}$ & $\begin{array}{l}\text { Group 1: Continuous ergometer cycling at } 60 \% \text { of } \\
\text { Wmax ( } 40 \mathrm{~min} \text { ); } \\
\text { Group 2: Upper and lower extremity strength exercise, } \\
\text { 6-8 weight lifting repetitions at } 70-85 \% \text { of one } \\
\text { repetition maximum; } \\
\text { Group 3: Combined endurance and strength exercise } \\
\text { (half of programme of group } 1 \text { and } 2 \text { ) }\end{array}$ & $\begin{array}{l}\text { Sessions of } 40 \mathrm{~min} \text {, } \\
3 \times / \text { week for } 12 \text { weeks, Edu }\end{array}$ & IET, CWRT, SWT, CRQ, BDI \\
\hline Spruit $^{34}$ & $\begin{array}{l}30 \text { COPD patients ( } 80 \% \text { men, } \\
\text { mean } F E V_{1} 40.5 \% \text { predicted, } \\
\text { mean age } 63 \text { years) }\end{array}$ & $\begin{array}{l}\text { Group 1: Continuous ergometer cycling at } 30-75 \% \text { of } \\
\text { Wmax ( } 10-25 \text { minutes), treadmill walking at } 60 \% \text { of } \\
\text { average speed in } 6 \mathrm{MWT} \text { ( } 10-25 \text { minutes) and arm } \\
\text { cranking (4-9 minutes); } \\
\text { Group 2: Upper and lower extremity strength exercise, } \\
3 \times 8 \text { repetitions at } \geqslant 70 \% \text { of one repetition maximum }\end{array}$ & $\begin{array}{l}\text { Sessions of } 90 \text { min, } \\
3 \times / \text { week for } 12 \text { weeks }\end{array}$ & IET, 6MWT, CRQ, BDI, \\
\hline Wurttemberger ${ }^{38}$ & $\begin{array}{l}69 \text { COPD patients ( } 64 \% \text { men, } \\
\text { mean } \mathrm{FEV}, 57.2 \% \text { and } 38.5 \% \\
\text { predicted for non- and for } \\
\text { exercise desaturating patients, } \\
\text { mean age } 65 \text { years) }\end{array}$ & $\begin{array}{l}\text { Group 1: Continuous ergometer cycling at } 70 \% \text { of } \\
\text { Wmax ( } 20 \text { min); } \\
\text { Group 2: Upper and lower extremity strength exercise, } \\
2-4 \times 20-25 \text { repetitions at } 40 \% \text { of one repetition } \\
\text { maximum; } \\
\text { Group 3: Continuous ergometer cycling as group } 1 \text { and } \\
\text { strength training as group } 2\end{array}$ & $\begin{array}{l}\text { Sessions of } 20-45 \text { min, } \\
3 \times / \text { week for } 3 \text { weeks, } \\
\text { Psy, Rel }\end{array}$ & $\begin{array}{l}\text { IET, 6MWT, functional test } \\
\text { for daily activities }\end{array}$ \\
\hline Bernard $^{39}$ & $\begin{array}{l}36 \text { COPD patients ( } 78 \% \text { men, } \\
\text { mean } \mathrm{FEV}_{1} 42.5 \% \text { predicted, } \\
\text { mean age } 65 \text { years) }\end{array}$ & $\begin{array}{l}\text { Group 1: Continuous ergometer cycling at } 80 \% \text { of } \\
\text { Wmax ( } 30 \text { min); } \\
\text { Group 2: Continuous ergometer cycling as group 1 } \\
\text { upper and lower extremity strength exercise with 10-30 } \\
\text { repetitions at } 60-80 \% \text { of one repetition maximum }\end{array}$ & $\begin{array}{l}\text { Sessions of } 30-60 \text { min, } \\
3 \times / \text { week for } 12 \text { weeks, } \\
\text { BE, Rel }\end{array}$ & $\begin{array}{l}\text { IET, 6MWT, CRQ, muscle } \\
\text { strength, muscle mass (CT } \\
\text { scan) }\end{array}$ \\
\hline Mador $^{40}$ & $\begin{array}{l}24 \mathrm{COPD} \text { patients (\% men not } \\
\text { stated, mean } \mathrm{FEV}, 41.8 \% \\
\text { predicted, mean age } 71 \text { years) }\end{array}$ & $\begin{array}{l}\text { Group 1: Continuous ergometer cycling at } \geqslant 50 \% \text { of } \\
\text { Wmax ( } 20 \mathrm{~min})+ \text { treadmill walking at } 1.1-2 \text { miles } \\
\text { per hour ( } 15 \mathrm{~min}) \text {; } \\
\text { Group 2: Continuous ergometer cycling as group } 1+ \\
\text { upper and lower extremity strength exercise with } 10 \\
\text { repetitions at } 60 \% \text { of one repetition maximum }\end{array}$ & $\begin{array}{l}\text { Sessions of } 60-90 \mathrm{~min}, \\
3 \times / \text { week for } 8 \text { weeks, Edu }\end{array}$ & $\begin{array}{l}\text { IET, CWRT, } 6 \mathrm{MWT} \text {, muscle } \\
\text { strength, CRQ }\end{array}$ \\
\hline $\operatorname{Ries}^{41}$ & $\begin{array}{l}28 \text { COPD patients ( } \% \text { men not } \\
\text { stated, mean } \mathrm{FEV}, 35.3 \% \\
\text { predicted, mean age not stated) }\end{array}$ & $\begin{array}{l}\text { Group 1: Treadmill walking, intensity set during } \\
\text { CWRT for } 15 \text { minutes, but no further details; } \\
\text { Group 2: Walking training as group } 1 \\
\text { + low } \\
\text { resistance high repetition exercises for upper } \\
\text { extremities (gravity resistance); } \\
\text { Group 3: Walking training as groups } 1+\text { low frequency } \\
\text { progressive resistance training for upper extremities } \\
\text { (proprioceptive neuromuscular facilitation) }\end{array}$ & $\begin{array}{l}\text { Sessions of } 15-30 \text { min, } \\
\text { unclear number/week for } \\
6 \text { weeks, Edu, BE, Psy, }\end{array}$ & $\begin{array}{l}\text { IET, Borg scale, Activities of } \\
\text { Daily Living test, muscle } \\
\text { strength }\end{array}$ \\
\hline Sivori ${ }^{42}$ & $\begin{array}{l}43 \text { COPD patients ( } 89 \% \text { men, } \\
\text { mean } F E V_{1} 36.1 \% \text { predicted, } \\
\text { mean age } 65 \text { years) }\end{array}$ & $\begin{array}{l}\text { Group 1: Continuous ergometer cycling at } 75 \% \text { of } \\
\text { Wmax (duration unclear); } \\
\text { Group 2: Continuous ergometer cycling as group } 1+ \\
\text { five upper extremities strength exercises with five } \\
\text { repetitions of } 45 \mathrm{~s}\end{array}$ & $\begin{array}{l}\text { Sessions of } 45 \mathrm{~min}, \\
3 \times / \text { week for } 8 \text { weeks }\end{array}$ & IET, 12MWT, CRQ \\
\hline
\end{tabular}

Wmax, maximum exercise capacity; IET, incremental exercise test; CWRT, constant work rate test; 6MWT and 12MWT, 6 and 12 minute walk test; SWT, shuttle walk test; Edu, education; BE, breathing exercises; Psy, psychological support; Rel, relaxation exercises; CRQ, Chronic Respiratory Questionnaire; BDI and TDI, baseline and transitional dyspnoea index.

improvements with strength exercise for all CRQ domains (fig 2). The differences were statistically significant for the emotional function domain $(-0.38,95 \%$ CI -0.01 to -0.74$)$ and for the CRQ total score $(-0.27,95 \%$ CI -0.02 to -0.52$)$. One trial ${ }^{37}$ found larger improvements in functional exercise capacity using shuttle walk tests for the group with strength exercise ( $70 \mathrm{~m}, 95 \% \mathrm{CI}-19$ to 159$)$, but the variability in the results was much larger than in the trials that used 6 minute walking tests. Three trials showed greater improvement in 6 minuts walking distance for patients with endurance exercise (fig 3), but the weighted mean difference did not reach statistical significance $(15 \mathrm{~m}, 95 \% \mathrm{CI}-14$ to 44$)$. The endurance exercise group showed larger improvements in maximum exercise capacity in one trial ${ }^{37}$ (mean difference between endurance and strength exercise groups of 6 Watt, $95 \%$ CI -2.2 to 14.2 ), while there were similar improvements for endurance and strength exercise in another trial ${ }^{34}$ (mean difference -1 Watt, 95\% CI -11.5 to 9.5). Two trials showed significantly larger improvements in exercise time during constant work rate tests for the strength exercise group (5.7 minutes, 95\% CI 3.0 to $8.4,{ }^{36}$ and 25.3 minutes, 95\% CI
12.7 to $37.9^{37}$ ). Ortega et $a l^{37}$ and Normandin et $a l^{36}$ found significantly larger improvements in skeletal muscle strength in the strength exercise group while Spruit et $a b^{34}$ observed similar improvements in both groups. The exercise programmes of Spruit et al differed from those of Normandin et al and Ortega et al in that patients had two types of endurance training (table 1) which may have resulted in a crossover effect leading to an absence of differences between the strength and endurance exercise groups. However, the number of trials was too small to assess this source of heterogeneity statistically.

The number of patients not completing the exercise programme was similar in groups with endurance (Normandin, $\mathrm{n}=7$; Ortega, $\mathrm{n}=2$; and Spruit, $\mathrm{n}=8$ ) and strength exercise (Normandin, $\mathrm{n}=7$; Ortega, $\mathrm{n}=1$; and Spruit, $\mathrm{n}=10$ )

Endurance exercise $v$ endurance + strength exercise Six articles ${ }^{37-42}$ reported on seven RCTs comparing endurance exercise only with endurance plus strength exercise (table 1). Wurttemberger presented the results of patients with and 


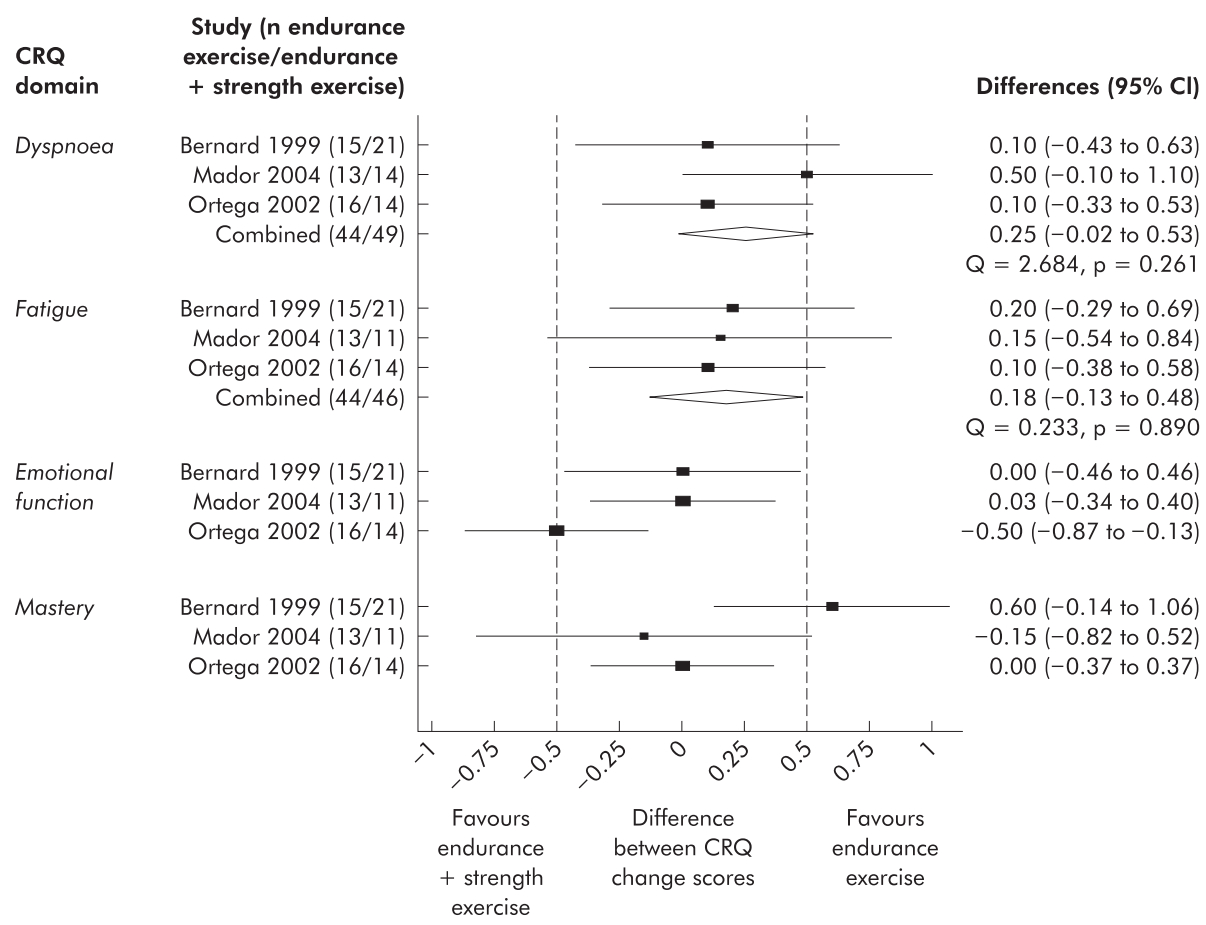

Figure 4 Results from three trials in which the $C R Q$ was used to compare a combination of endurance and strength exercise with endurance exercise alone. Boxes with 95\% confidence intervals represent point estimates for the difference between the CRQ change scores (from baseline to follow up) of the study groups. A difference of 0 means that both study groups improved or deteriorated to the same amount. Results are presented per CRQ domain. Dashed lines at \pm 0.5 represent the minimal important difference of the CRQ.

without oxygen desaturation during exercise separately in one article. ${ }^{38}$ Five trials $\mathrm{s}^{37-40}$ had similar exercise protocols for the study groups with endurance only or combined endurance plus strength exercise. There were no differences between groups in terms of HRQL or functional and maximum exercise capacity improvements (figs 4 and 5). Improvements in exercise endurance were similar in both groups in one trial $^{40}$ (mean difference between endurance exercise alone and combined endurance and strength exercise group $-0.3,95 \% \mathrm{CI}-8.1$ to 7.5$)$, while another trial $^{37}$ showed larger, although statistically not significant, improvements in the endurance exercise group (mean difference 9.6 minutes, $95 \%$ CI -3.9 to 23.1 ). The larger improvements in muscle strength in the groups with endurance plus strength exercise as reported in three trials $^{37} 39{ }^{40}$ did not therefore translate into additional benefits in terms of HRQL or exercise capacity.

\section{Continuous $v$ interval exercise}

Three trials compared continuous and interval exercise (tables 2 and 3)..$^{35}{ }^{44}$ One trial ${ }^{43}$ found a larger increase in peak oxygen consumption and lower lactate levels at submaximal exercise intensity with continuous exercise than with interval exercise. In contrast, only interval exercise led to significant increases in maximum exercise capacity and decrease of leg pain during exercise. $91 \%$ of patients with continuous exercise and $90 \%$ of patients with interval exercise completed the exercise programme. In another trial ${ }^{35}$ HRQL, maximum exercise capacity, and peak oxygen uptake improved significantly in both groups without significant differences between them. Attendance rate for exercise sessions was $88 \%$ for continuous exercise and $90 \%$ for interval exercise in this trial. Finally, in the third trial ${ }^{44}$ patients with interval exercise had a trend towards larger improvements in 6 minute walking distance compared with patients with continuous exercise.

\section{Other comparisons}

Rooyackers et $a l^{45}$ assessed the additional value of eccentric exercise (negative work) when added to interval exercise (table 2). Patients tolerated additional eccentric exercise for 15 minutes at moderate to high intensity (mean 69\% of maximum exercise capacity) well (Borg dyspnoea score $\leqslant 3$ ), but this did not lead to improvements in HRQL or exercise capacity (table 3 ). The only significant difference favouring additional eccentric exercise existed for oxygen tension at maximum exercise capacity $(7.9 v 6.9 \mathrm{kPa}, \mathrm{p}<0.05)$.

Martinez et $a l^{46}$ compared the effects of supported (arm ergometer exercise) and unsupported upper extremity exercises (dowel lifting exercises resembling daily activities) when added to a lower extremity endurance and respiratory muscle training (table 2). Both the group with and those without supported arm exercise significantly improved functional and maximum exercise capacity as well as respiratory muscle strength to a similar degree. Improvements in power output during arm ergometry were similar for both groups while patients with unsupported arm exercises had a significantly larger increase in unsupported arm endurance and a decrease in oxygen consumption.

\section{Comparisons of training intensities}

One small trial ${ }^{47}$ compared the effect of high and low intensity exercise in middle aged patients with mild COPD (table 2). The trial showed that high intensity exercise at $80 \%$ of maximum exercise capacity yielded a bigger physiological response in terms of reductions in exercise induced lactate acidosis and ventilation (table 3 ). The larger training effect after high intensity exercise led also to longer endurance time.

Vallet et $a l^{48}$ (table 2) assessed whether exercise at the individual anaerobic threshold was more effective than exercise at $50 \%$ of the maximal heart rate reserve (standardised protocol). Mean exercise intensities between the groups 


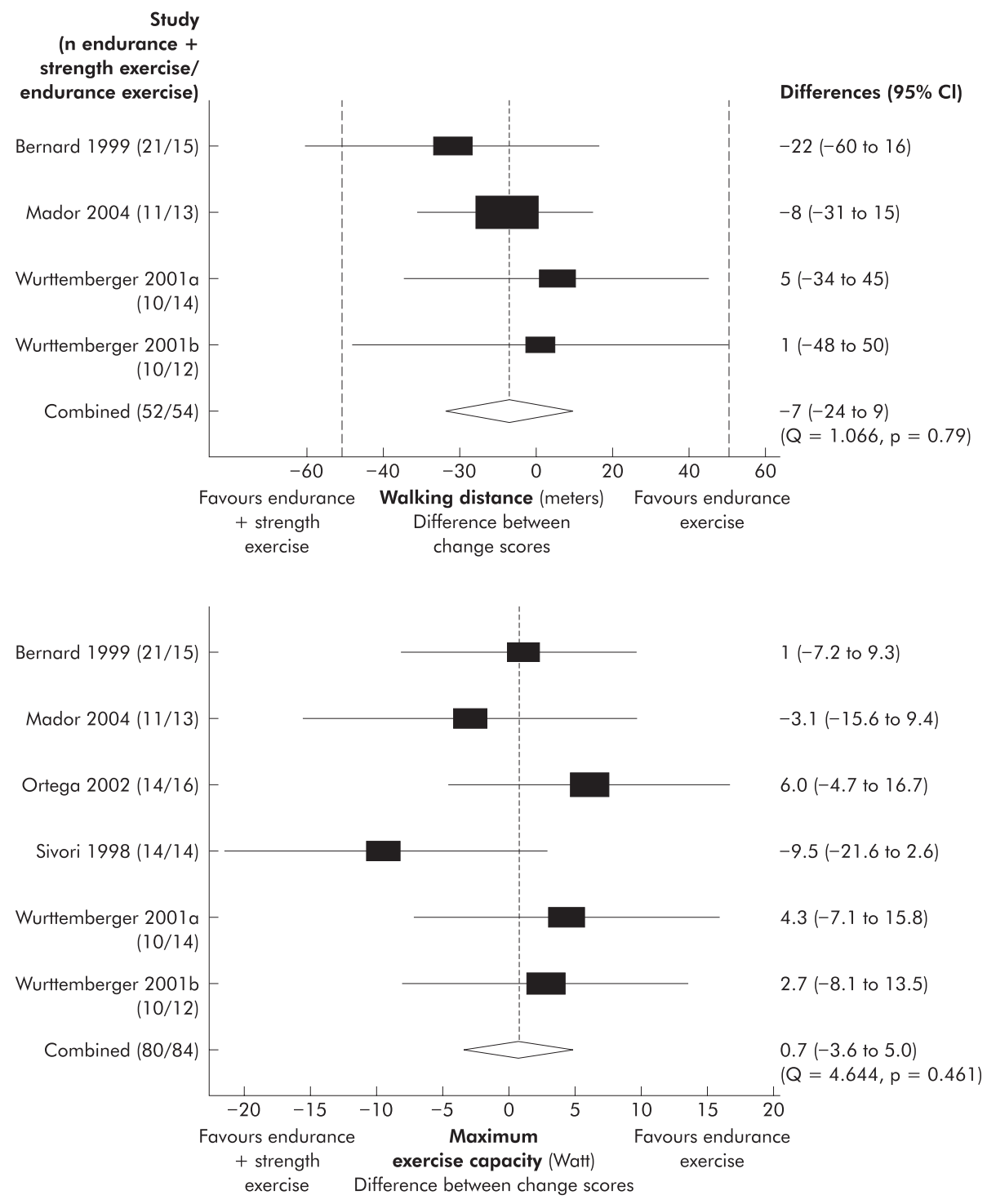

Figure 5 Results from six trials in which walking tests and incremental exercise tests were used to compare a combination of endurance and strength exercise with endurance exercise alone. Boxes with $95 \%$ confidence intervals represent point estimates for the difference between the walking distances and maximum exercise capacity change scores (from baseline to follow up) of the study groups. A difference of 0 means that both study groups improved or deteriorated to the same amount. Dashed lines at \pm 53 meters represent the minimal important difference of the six-minute walk test.

were not different. The authors reported a trend towards larger increases of peak oxygen uptake and anaerobic threshold with the individualised exercise protocol (table 3). There was a significantly greater training response in the group with the individualised protocol in terms of reductions in minute ventilation, lactate levels, and carbon dioxide output at given levels of pre-training oxygen uptake (data available only from figures).

\section{DISCUSSION}

There are three principal results from this systematic review. Firstly, strength exercise yielded larger improvements in HRQL than endurance exercise. Secondly, interval exercise may represent an alternative to continuous exercise but the methodological quality of the evidence is low and does not favour one or other exercise modality. Finally, there is only low quality evidence that high intensity exercise is superior to low intensity exercise.

In general, only few trials addressed important aspects of study design such as methods of randomisation and concealment of random allocation. While blinding of patients and therapists is hardly possible in respiratory rehabilitation programmes (items rated as not applicable), blinding of outcome assessors is feasible as in any other RCT. There are empirical data that lack of blinding is associated with significant bias. $^{4950}$ Only one trial, ${ }^{34}$ however, reported blinding of outcome assessors. Thus, one needs to bear in mind the limited methodological quality of included trials for the following discussion.

In clinical practice and in clinical trials, most rehabilitation programmes include endurance exercise, but not always strength exercise. ${ }^{6}$ Although investigators and clinicians have discussed the importance of peripheral muscle strength for daily activities repeatedly, there is no consensus on the role of strength exercise during respiratory rehabilitation. ${ }^{10245152}$ Data tend to suggest, however, that strength exercise should be considered likewise. Strength exercise led to larger improvements in HRQL than endurance exercise (fig 2). There is some evidence that muscle strength is associated with HRQL, ${ }^{53}$ which would explain the effect of strength 
Table 2 Characteristics of randomised controlled trials comparing exercise modalities and intensities

\begin{tabular}{|c|c|c|c|c|}
\hline Study & Population & Exercise programmes & Rehabilitation programme & Outcomes \\
\hline Coppoolse $^{43}$ & $\begin{array}{l}21 \text { male COPD patients (mean } \\
\mathrm{FEV}, 36.8 \% \text { predicted, mean } \\
\text { age } 65 \text { years) }\end{array}$ & $\begin{array}{l}\text { Group 1: Continuous ergometer cycling at } \\
60 \% \text { of Wmax; } \\
\text { Group 2: Interval ergometer cycling at } 90 \% \text { of } \\
\text { Wmax (1 min) and } 45 \% \text { of Wmax ( } 2 \mathrm{~min} \text { ) } \\
3 \text { days/week plus continuous ergometer cycling } \\
\text { at } 60 \% \text { of Wmax } 2 \text { days/week }\end{array}$ & $\begin{array}{l}\text { Sessions of } 30 \mathrm{~min}, 5 \times / \text { week for } \\
8 \text { weeks, Edu }\end{array}$ & IET, CWRT, Borg scale \\
\hline Vogiatzis $^{35}$ & $\begin{array}{l}45 \text { COPD patients }(62 \% \text { men, mean } \\
\text { FEV } 134.1 \% \text { predicted, mean age } \\
65 \text { years) }\end{array}$ & $\begin{array}{l}\text { Group 1: Continuous ergometer cycling at } \\
50 \% \text { of Wmax weeks 1-4, at } 60 \% \text { weeks } 5-8 \\
\text { and at } 70 \% \text { weeks } 9-12 \text {; } \\
\text { Group 2: Interval ergometer cycling at } 100 \% \text { of } \\
\text { Wmax ( } 30 \text { s) and } 45 \% \text { of Wmax ( } 30 \text { s) weeks } 1- \\
4 \text {, at } 120 \% \text { weeks } 5-8 \text { and at } 140 \% \text { weeks } 9-12\end{array}$ & $\begin{array}{l}\text { Sessions of } 40 \mathrm{~min}, 2 \times / \text { week for } \\
12 \text { weeks, Edu, BE, Psy, Rel } \\
\text { f } \\
-\end{array}$ & IET, Borg scale, CRQ \\
\hline Kaelin $^{44}$ & $\begin{array}{l}19 \text { COPD patients ( } 89 \% \text { men, mean } \\
\text { FEV } 126.9 \% \text { predicted, mean age } \\
67 \text { years) }\end{array}$ & $\begin{array}{l}\text { Group 1: Continuous walking on stepper ( } 70 \\
\text { steps/minute) or treadmill ( } 1.5 \text { miles/hour). } \\
\text { Increase of } 1 \text { MET every } 2 \text { weeks; } \\
\text { Group 2: Interval walking on stepper ( } 70 \text { steps/ } \\
\text { minute) or treadmill (1.5 miles/hour) with active } \\
\text { to rest ratio of } 2: 1 . \text { Increase of } 1 \text { MET every } \\
2 \text { weeks }\end{array}$ & $\begin{array}{l}\text { Sessions of } 10-30 \mathrm{~min}, 3 \times / \text { week } \\
\text { for } 6 \text { weeks, Edu, BE, Psy, Rel }\end{array}$ & 6MWT \\
\hline Martinez $^{46}$ & $\begin{array}{l}35 \mathrm{COPD} \text { patients ( } 40 \% \text { males, } \\
\text { mean } \mathrm{FEV}_{1} 32.1 \% \text { predicted, mean } \\
\text { age } \\
66 \text { years) }\end{array}$ & $\begin{array}{l}\text { Group 1: Ergometer cycling (10-30 min) + } \\
\text { supported arm exercises (arm ergometer } \\
{[\leqslant 15 \mathrm{~min}] \text { both at Borg dyspnoea score of } 3} \\
\text { ?and rating of perceived exertion of } 12-14) ; \\
\text { Group 2: Ergometer cycling (10-30 min) + } \\
\text { unsupported arm exercises (five exercises for } \\
\text { elbow flexion/extension, arm abduction/ } \\
\text { adduction and shoulder circles with wooden } \\
\text { dowels) }\end{array}$ & $\begin{array}{l}\text { Sessions of } 30 \mathrm{~min}, 3 \times / \text { week for } \\
10 \text { weeks, respiratory muscle } \\
\text { training ( } 15 \mathrm{~min} 2 / \text { day) }\end{array}$ & $\begin{array}{l}\text { IET, } 12 \mathrm{MWT} \text {, arm } \\
\text { ergometry and dowel lifting }\end{array}$ \\
\hline Rooyackers ${ }^{45}$ & $\begin{array}{l}24 \text { COPD patients ( } 83 \% \text { men, mean } \\
\text { FEV } 141.5 \% \text { predicted, mean age } \\
59 \text { years) }\end{array}$ & $\begin{array}{l}\text { Group 1: Interval ergometer cycling ( } 20 \mathrm{~min} \text {, } \\
\text { exercise/rest ratio } 2 \mathrm{~min} / 2 \mathrm{~min} \text { ) + upper and } \\
\text { lower extremity strength exercise; } \\
\text { Group 2: As for group } 1+\text { cycle ergometer } \\
\text { eccentric exercise ("negative work") at highest } \\
\text { intensity sustainable for } 15 \text { minutes }\end{array}$ & $\begin{array}{l}\text { Sessions of } 20-35 \mathrm{~min}, 5 \times / \text { week } \\
\text { for } 10 \text { weeks }\end{array}$ & IET, $6 M W T, C R Q$ \\
\hline Casaburi $^{47}$ & $\begin{array}{l}19 \text { male COPD patients (mean } \mathrm{FEV} \\
56 \% \text { predicted, mean age } 51 \text { years) }\end{array}$ & $\begin{array}{l}\text { Group 1: Continuous ergometer cycling at } \\
80 \% \text { of Wmax; } \\
\text { Group 2: Continuous ergometer cycling at } \\
40 \% \text { of Wmax }\end{array}$ & $\begin{array}{l}\text { Sessions of } 45 \mathrm{~min}, 5 \times / \text { week for } \\
8 \text { weeks, Edu }\end{array}$ & IET, CWRT \\
\hline Vallet $^{48}$ & $\begin{array}{l}24 \text { COPD patients }(75 \% \text { men, mean } \\
\text { FEV } 158.5 \% \text { predicted, mean age } \\
57 \text { years) }\end{array}$ & $\begin{array}{l}\text { Group 1: Standardised exercise protocol with } \\
\text { continuous ergometer cycling at } 50 \% \text { of } \\
\text { maximum heart reserve (= maximum heart } \\
\text { rate - heart rate at rest) } / 2+\text { heart rate at rest); } \\
\text { Group 2: Individualised exercise protocol with } \\
\text { continuous ergometer cycling at the individual } \\
\text { gas exchange threshold (anaerobic threshold) }\end{array}$ & $\begin{array}{l}\text { Sessions of } 45 \mathrm{~min}, 5 \times / \text { week for } \\
4 \text { weeks, Edu, BE }\end{array}$ & IET \\
\hline
\end{tabular}

Wmax, maximum exercise capacity; IET, incremental exercise test; CWRT, constant work rate test; 6 and 12MWT, 6 and 12 minute walk test; Edu, education; BE, breathing exercises; Psy, psychological support; Rel, relaxation exercises; CRQ, Chronic Respiratory Questionnaire; BDI and TDI, baseline and transitional dyspnoea index; PFSS, pulmonary function status scale.

exercise on the CRQ fatigue, emotional function and mastery domains (fig 2). However, more studies are needed to confirm this potential association.

The trials comparing endurance and a combination of endurance and strength exercise showed less clear results (figs 4 and 5). One could attribute this finding to the fact that patients in both intervention groups had the same intervention in most trials (endurance exercise), which led to similar effects. Specific strength training effects were also observed when strength exercise was added, ${ }^{37}{ }^{40}$ but the contrast between groups appeared to be too small to show differences in terms of HRQL, even in pooled analyses.

Interval exercise is considered to be a promising approach to provide sustainable high intensity exercise for COPD patients because it allows for short periods of recovery preventing high lactate accumulation. ${ }^{24}{ }^{54}$ There is some evidence of this from three RCTs ${ }^{35} 43$ comparing interval exercise and continuous exercise. The results indicate that both modalities improved exercise capacity, dyspnoea, and HRQL to a similar degree. However, the non-significant differences between treatment groups do not allow us to conclude that interval or continuous exercise are of clinically equivalent effectiveness. ${ }^{55}$ These trials were not designed to show clinical equivalence and they did not provide evidence that interval exercise is better tolerated. In one trial with an inpatient rehabilitation programme, ${ }^{43}$ patients in the interval exercise group had a mixed intervention ( 3 days of interval and 2 days of continuous exercise per week) so that differences cannot be attributed to different interventions even if they were detected. Although interval exercise may offer an attractive alternative for COPD patients, more trials are needed with rigorous methodology and outcomes which consider the relative effectiveness and tolerance of interval exercise compared with continuous exercise.

A surprising finding of this review is that evidence favouring high intensity over low intensity exercise is weak. High intensity exercise is usually defined as exercise at $\geqslant 60$ $90 \%$ of the maximum exercise capacity, but there is no consensus on the lower or upper limit to define high intensity exercise. ${ }^{24}$ There is one frequently cited trial ${ }^{47}$ comparing high and low intensity exercise that was small and had several methodological limitations (see online data). The reductions in lactate acidosis and larger improvements in exercise endurance were not reproduced in later trials nor are any data available on the effect of high and low intensity exercise on HRQL and other patient outcomes. It is also uncertain whether the results from this single trial ${ }^{47}$ apply to patients with moderate to severe COPD, because these patients are often unable to sustain high intensity exercise even though they achieve significant improvements in exercise capacity with lower exercise intensities. ${ }^{565}$ Future research should therefore look at the intensity at which patients with COPD 
Table 3 Effect of different exercise intensities

\begin{tabular}{|c|c|c|c|}
\hline Study (no of patients in each group) & Outcome measure & $\begin{array}{l}\text { Difference follow up minus } \\
\text { baseline for each group }\end{array}$ & $\begin{array}{l}\text { Difference between groups } \\
\text { (95\% Cl where available) }\end{array}$ \\
\hline \multirow{6}{*}{$\begin{array}{l}\text { Coppoolse }^{43} \\
\text { (CE } n=11 ; \text { IE } n=10 \text { ) }\end{array}$} & Wmax (Watts) & CE: $8 ;$ IE: 13 & $-5, p>0.05$ \\
\hline & Peak oxygen uptake $\left(\mathrm{VO}_{2}, \mathrm{I} / \mathrm{min}\right)$ & CE: 0.15 ; IE: 0.07 & $0.08, p>0.05$ \\
\hline & Lactate at sub-maximum exercise capacity & CE: $-31 \%$; IE: $-20 \%$ & $-11 \%, p>0.05$ \\
\hline & Leg pain at Wmax & CE: $-13 \%$; IE: $-26 \%$ & $13 \%, p>0.05$ \\
\hline & Dyspnoea at Wmax & CE: $-2 \%$; IE: $-15 \%$ & $13 \%, p>0.05$ \\
\hline & $\begin{array}{l}\text { Raw data only for the whole study group } \\
\text { available but not for each group. Changes } \\
\text { within continuous and interval exercise group } \\
\text { only in percentages }\end{array}$ & & \\
\hline \multirow[t]{9}{*}{$\begin{array}{l}\text { Vogiatzis }^{35} \\
\text { (CE } n=18 ; \text { IE } n=18 \text { ) }\end{array}$} & $\begin{array}{l}C R Q \text { Dyspnoea (raw data for CRQ scores } \\
\text { only from figures available) }\end{array}$ & CE: $1.7 ; \mathrm{IE}: 1.2$ & $0.5(p>0.05)$ \\
\hline & $C R Q$ Fatigue & CE: 0.6 ; IE: 0.6 & $0.0(p>0.05)$ \\
\hline & $C R Q$ Emotional function & CE: 0.6 ; IE: 0.4 & $0.2(p>0.05)$ \\
\hline & CRQ Mastery & CE: 0.4 ; IE: 0.4 & $0.0(p>0.05)$ \\
\hline & Wmax (Watts) & CE: 13; IE: 14 & $-1(p>0.05)$ \\
\hline & Dyspnoea at Wmax (VAS) & CE: -3 ; IE: -4 & $1(p>0.05)$ \\
\hline & Peak oxygen uptake $\left(\mathrm{VO}_{2}, \mathrm{I} / \mathrm{min}\right)$ & CE: 0.13 ; IE: 0.12 & $0.01(p>0.05)$ \\
\hline & Ventilation at peak exercise intensity $(1 / \mathrm{min})$ & CE: $-3.9 ;$ IE: -4.1 & $0.2(p>0.05)$ \\
\hline & Lactate threshold (I/min) & CE: 0.12 ; IE: 0.11 & $0.01(p>0.05)$ \\
\hline $\begin{array}{l}\text { Kaelin }^{44} \\
\text { (CE } n=6 ; \text { IE } n=7 \text { ) }\end{array}$ & $6 \mathrm{MWD}(\mathrm{m})$ & CE: 39; IE: 80 & $41(-17$ to 99$)$ \\
\hline \multirow{6}{*}{$\begin{array}{l}\text { Rooyackers } \\
(\mathrm{IE} n=12 ; \mathrm{IE}+\mathrm{EE} n=12)\end{array}$} & CRQ Dyspnoea & IE: 1.34 ; IE +EE: 0.86 & $0.48(-0.20$ to 1.16$)$ \\
\hline & CRQ Fatigue & IE: 0.65 ; IE +EE: 1.0 & $-0.35(-0.74$ to 0.04$)$ \\
\hline & CRQ Emotional function & IE: 0.46 ; IE +EE: 0.59 & $-0.13(-0.67$ to 0.41$)$ \\
\hline & CRQ Mastery & $\mathrm{IE}: 0.60$; IE +EE: 1.05 & $-0.45(-0.98$ to 0.08$)$ \\
\hline & Wmax (Watts) & IE: 17.0; IE +EE: 10.0 & $7.0(-3.87$ to 17.87$)$ \\
\hline & $6 \mathrm{MWD}(\mathrm{m})$ & IE: 123; IE +EE: 118 & $5(-60$ to 70$)$ \\
\hline \multirow[t]{5}{*}{$\begin{array}{l}\text { Casaburi }^{47} \\
(\mathrm{HIE} n=11 ; \text { LIE } n=8)\end{array}$} & $\begin{array}{l}\text { Exercise duration (in minutes) during CWRT } \\
\text { at } 40 \% \text { of } W \max \end{array}$ & HIE: 2.1 ; LIE: 1.6 & $0.5(p>0.05)$ \\
\hline & $\begin{array}{l}\text { Exercise duration (minutes) during CWRT } \\
\text { at } 80 \% \text { of Wmax }\end{array}$ & HIE: 4.8 ; LIE: 0.6 & $4.2(p<0.05)$ \\
\hline & Lactate $(\mathrm{mEq} / \mathrm{l})$ at $\mathrm{W} \max$ & HIE: $-2.7 ;$ LIE: -1.0 & $-1.7(p<0.01)$ \\
\hline & Lactate threshold (I/min) & HIE: 0.18 ; LIE: 0.08 & $0.1(p>0.05)$ \\
\hline & Ventilation VE $(1 / \mathrm{min})$ & HIE: -6.4 ; LIE: -0.1 & $-6.3(p<0.005)$ \\
\hline Vallet $^{48}$ & Peak oxygen uptake $\left(\mathrm{VO}_{2}, \mathrm{I} / \mathrm{min}\right)$ & SE: 0.17 ; IE: 0.31 & -0.14 \\
\hline (SE $n=12 ; \mathrm{IE} n=12$ ) & Anaerobic threshold (ml/kg/min) & SE: 1.2; IE: 3.2 & $-2.0(p<0.05)$ \\
\hline
\end{tabular}

should and can exercise to achieve patient important training effects and explore the influence of baseline disease severity.

In conclusion, strength exercise tends to improve HRQL more than endurance exercise. More research is needed to assess the relative benefits and disadvantages of interval exercise compared with continuous exercise and to define optimal exercise intensity for patients with COPD. Future studies should be planned and executed with more care to allow assessment of the variability in response to exercise and to provide more robust estimates of differences between the effects of exercise protocols.

\section{ACKNOWLEDGEMENTS}

The authors thank Dr Pius Estermann, Information Officer, University Hospital of Zurich who designed and conducted the searches of electronic databases.

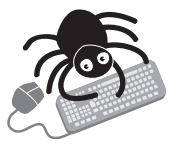

Data on the validity of the included studies are available online at the Thorax website at http:// www.thoraxinl.com/supplemental.

\section{Authors' affiliations}

M A Puhan, M Scharplatz, L M Bachmann, Horten Centre, University of Zurich, Switzerland

H J Schünemann, University at Buffalo, Departments of Medicine and of Social and Preventive Medicine, New York, USA

H J Schünemann, McMaster University, Department of Clinical Epidemiology and Biostatistics, McMaster University, Hamilton, Ontario, Canada
M Frey, Klinik Barmelweid, Department of Respiratory Medicine, Barmelweid, Switzerland

L M Bachmann, University of Berne, Department of Social and Preventive Medicine, Berne, Switzerland

Funding: Helmut Horten Foundation Research Fellows and Swiss National Science Foundation (PROSPER programme) grant numbers 3233B0-103182 and 3233B0-103183, L M Bachmann.

Competing interests: none declared.

Contributors: Study concept and design (MAP, LMB); study retrieval and data extraction (MAP, LMB, MS); analysis and interpretation of data (MAP, LMB, MF, HJS); drafting of manuscript (MAP); critical revision of manuscript for important intellectual content (LMB, MF, HJS, MS).

\section{REFERENCES}

1 World Health Organisation. World health report 2000. Geneva: World Health Organisation, 2000, www.who.int/whr/2000/en/statistics.htm.

2 Seemungal T, Donaldson G, Paul E, et al. Effect of exacerbation on quality of life in patients with chronic obstructive pulmonary disease. Am J Respir Crit Care Med 1998;157:1418-22.

3 Sin DD, Stafinski T, Ng YC, et al. The impact of chronic obstructive pulmonary disease on work loss in the United States. Am J Respir Crit Care Med 2002; 165:704-7.

4 Sullivan SD, Ramsey SD, Lee TA. The economic burden of COPD. Chest 2000;117:5S-9S

5 Decramer M, Gosselink R, Troosters T, et al. Muscle weakness is related to utilization of health care resources in COPD patients. Eur Respir $J$ 1997; 10:417-23.

6 Lacasse Y, Brosseau L, Milne S, et al. Pulmonary rehabilitation for chronic obstructive pulmonary disease. Cochrane Database Syst Rev, 2002; CD003793.

7 Griffiths TL, Phillips CJ, Davies S, et al. Cost effectiveness of an outpatient multidisciplinary pulmonary rehabilitation programme. Thorax 2001;56:779-84.

8 Anthonisen NR, Wright EC, Hodgkin JE. Prognosis in chronic obstructive pulmonary disease. Am Rev Respir Dis 1986;133:14-20. 
9 Celli BR, Cote CG, Marin JM, et al. The body-mass index, airflow obstruction, dyspnea, and exercise capacity index in chronic obstructive pulmonary disease. N Engl J Med 2004;350:1005-12.

10 Hamilton AL, Killian KJ, Summers E, et al. Muscle strength, symptom intensity, and exercise capacity in patients with cardiorespiratory disorders. Am J Respir Crit Care Med 1995; 152:2021-31.

11 Marquis K, Debigare R, Lacasse Y, et al. Midthigh muscle cross-sectional area is a better predictor of mortality than body mass index in patients with chronic obstructive pulmonary disease. Am J Respir Crit Care Med 2002;166:809-13.

12 Bernard S, LeBlanc $P$, Whittom F, et al. Peripheral muscle weakness in patients with chronic obstructive pulmonary disease. Am J Respir Crit Care Med 1998; 158:629-34.

13 American College of Chest Physicians/American Association of Cardiovascular and Pulmonary Rehabilitation. Pulmonary rehabilitation: joint ACCP/AACVPR evidence-based guidelines. ACCP/AACVPR Pulmonary Rehabilitation Guidelines Panel. Chest 1997;1 12:1363-96.

14 Anon. Pulmonary rehabilitation. Thorax 2001;56:827-34.

15 British Thoracic Society. BTS guidelines for the management of chronic obstructive pulmonary disease. Thorax 1997;52(Suppl 5):S1-28.

16 National Heart, Lung and Blood Institute. Global strategy for the diagnosis, management and prevention of chronic obstructive pulmonary disease. Bethesda, MD: National Heart, Lung and Blood Institute, 2003, http:// www.goldcopd.com.

17 American Thoracic Society. Pulmonary rehabilitation:1999. Am J Respir Crit Care Med 1999; 159:1666-82.

18 Mador MJ, Bozkanat E. Skeletal muscle dysfunction in chronic obstructive pulmonary disease. Respir Res $2001 ; 2: 216-24$.

19 American Thoracic Society/European Respiratory Society. Skeletal muscle dysfunction in chronic obstructive pulmonary disease. A statement of the American Thoracic Society and European Respiratory Society. Am J Respir Crit Care Med 1999;159:S1-40.

20 Goldstein RS, Gort EH, Stubbing D, et al. Randomised controlled trial of respiratory rehabilitation. Lancet 1994;344:1394-7.

21 Lake FR, Henderson K, Briffa T, et al. Upper-limb and lower-limb exercise training in patients with chronic airflow obstruction. Chest 1990;97:1077-82.

22 Troosters T, Gosselink R, Decramer M. Short- and long-term effects of outpatient rehabilitation in patients with chronic obstructive pulmonary disease: a randomized trial. Am J Med 2000;109:207-12.

23 Wijkstra PJ, van Altena R, Kraan J, et al. Quality of life in patients with chronic obstructive pulmonary disease improves after rehabilitation at home. Eur Respir J 1994;7:269-73.

24 Gosselink R, Troosters T, Decramer M. Exercise training in COPD patients: the basic questions. Eur Respir J 1997; 10:2884-91.

25 American College of Sports Medicine. The recommended quantity and quality of exercise for developing and maintaining cardiorespiratory and muscular fitness in healthy adults. Med Sci Sports Exerc 1990;22:265-74.

26 ter-Riet G, Kessels AGH. Commentary on Rampes et al 'Does electroacupuncture reduce craving for alcohol? A randomized controlled study'. Complement Therap Med, 1997;1 16-8.

27 Schunemann HJ, Puhan MA, Goldstein R, et al. Measurement properties and interpretability of the Chronic Respiratory Disease Questionnaire (CRQ). J Chronic Obstruct Pulmon Dis 2005;2:81-9.

28 Redelmeier DA, Bayoumi AM, Goldstein RS, et al. Interpreting small differences in functional status: the six minute walk test in chronic lung disease patients. Am J Respir Crit Care Med 1997;155:1278-82.

29 Jaeschke R, Singer J, Guyatt GH. Measurement of health status. Ascertaining the minimal clinically important difference. Control Clin Trials 1989;10:407-15.

30 Schunemann HJ, Griffith L, Jaeschke R, et al. Evaluation of the minimal important difference for the feeling thermometer and the St George's Respiratory Questionnaire in patients with chronic airflow obstruction. J Clin Epidemiol 2003;56:1 170-6

31 Arnardottir RH, Larsson K, Ringqvist I, et al. Endurance training compared to non-endurance training in chronic obstructive pulmonary disease (COPD). A randomized controlled trial. Am J Respir Crit Care Med 2001;163(Suppl 5):A647.

32 Baarends EM, Creutzberg EC, Janssen PP, et al. Functional effects of unsupported arm exercise training (UAE) in addition to nutritional therapy in depleted patients with chronic obstructive pulmonary disease (COPD) participating in a pulmonary rehabilitation program. Eur Respir $J$ 1999;13(Suppl 30):211S.
33 Shu MF, Kao CH, Kuo HP. Upper arm exercise improves exercise tolerance and dyspnea sensation in patients with chronic obstructive airway disease (COAD). Eur Respir J 1998;12(Suppl 28):406S.

34 Spruit MA, Gosselink R, Troosters T, et al. Resistance versus endurance training in patients with COPD and peripheral muscle weakness. Eur Respir J 2002; 19:1072-8.

35 Vogiatzis I, Nanas S, Roussos C. Interval training as an alternative modality to continuous exercise in patients with COPD. Eur Respir J 2002;20:12-9.

36 Normandin EA, McCusker C, Connors M et al. An evaluation of two approaches to exercise conditioning in pulmonary rehabilitation. Chest 2002;121:1085-91

37 Ortega F, Toral J, Cejudo P, et al. Comparison of effects of strength and endurance training in patients with chronic obstructive pulmonary disease. Am J Respir Crit Care Med 2002;166:669-74.

38 Wurtemberger G, Bastian K. Functional effects of different training in patients with COPD. Pneumologie 2001;55:553-62.

39 Bernard S, Whittom F, LeBlanc $P$, et al. Aerobic and strength training in patients with chronic obstructive pulmonary disease. Am J Respir Crit Care Med 1999;159:896-901.

40 Mador MJ, Bozkanat E, Aggarwal A, et al. Endurance and strength training in patients with COPD. Chest 2004;125:2036-45.

41 Ries AL, Ellis B, Hawkins RW. Upper extremity exercise training in chronic obstructive pulmonary disease. Chest 1988;93:688-92.

42 Sivori M, Rhodius E, Kaplan P, et al. Exercise training in chronic obstructive pulmonary disease. Comparative study of aerobic training of lower limbs vs. combination with upper limbs. Medicina 1998;58:717-27.

43 Coppoolse R, Schols AM, Baarends EM, et al. Interval versus continuous training in patients with severe COPD: a randomized clinical trial. Eur Respir J 1999; 14:258-63.

44 Kaelin ME, Barnard K, Swank A, et al. Results of 6 minute ambulation and met tolerance of patients with severe chronic obstructive pulmonary disease (COPD) utilizing 2 different aerobic training regimes: interval training versus continuous training. American Society of Exercise Physiology 2nd Annual Meeting, 1997

45 Rooyackers JM, Berkeljon DA, Folgering HT. Eccentric exercise training in patients with chronic obstructive pulmonary disease. Int J Rehabil Res 2003;26:47-9

46 Martinez FJ, Vogel PD, Dupont DN, et al. Supported arm exercise vs unsupported arm exercise in the rehabilitation of patients with severe chronic airflow obstruction. Chest 1993;103:1397-402.

47 Casaburi R, Patessio A, loli $F$, et al. Reductions in exercise lactic acidosis and ventilation as a result of exercise training in patients with obstructive lung disease. Am Rev Respir Dis 1991;143:9-18.

48 Vallet G, Ahmaidi S, Serres I, et al. Comparison of two training programmes in chronic airway limitation patients: standardized versus individualized protocols. Eur Respir J 1997;10:114-22.

49 Kjaergard LL, Villumsen J, Gluud C. Reported methodologic quality and discrepancies between large and small randomized trials in meta-analyses. Ann Intern Med 2001; 135:982-9.

50 Schulz KF, Chalmers I, Hayes RJ, et al. Empirical evidence of bias. Dimensions of methodological quality associated with estimates of treatment effects in controlled trials. JAMA 1995;273:408-12.

51 Celli BR. Training in the rehabilitation of pulmonary patients with chronic obstructive pulmonary disease. Monaldi Arch Chest Dis 1998;53:438-49.

52 Donner CF, Muir JF. Selection criteria and programmes for pulmonary rehabilitation in COPD patients. Rehabilitation and Chronic Care Scientific Group of the European Respiratory Society. Eur Respir J 1997:10:744-57.

53 Toral MJ, Ortega F, Cejudo P, et al. Peripheral muscle strength in stable COPD patients: correlation with respiratory function variables and quality of life. Arch Bronconeumol 1999;35:117-21.

54 Spruit MA, Troosters T, Trappenburg JC, et al. Exercise training during rehabilitation of patients with COPD: a current perspective. Patient Educ Couns 2004;52:243-8.

55 Jones B, Jarvis P, Lewis JA, et al. Trials to assess equivalence: the importance of rigorous methods. BMJ 1996;313:36-9.

56 Maltais F, LeBlanc P, Simard C, et al. Skeletal muscle adaptation to endurance training in patients with chronic obstructive pulmonary disease. Am J Respir Crit Care Med 1996; 154:442-7.

57 Maltais $F$, LeBlanc $P$, Jobin J, et al. Intensity of training and physiologic adaptation in patients with chronic obstructive pulmonary disease. Am J Respir Crit Care Med 1997; 155:555-61. 